\title{
Sobre as maquetas - Ensaio visual
}

\author{
Ricardo Carvalho \\ rcarvalho@autonoma.pt \\ Departamento de Arquitetura, Universidade Autónoma de Lisboa
}

Para citação: CARVALHO, Ricardo - Sobre as maquetas. Estudo Prévio 16. Lisboa: CEACT/UAL - Centro de Estudos de Arquitetura, Cidade e Território da Universidade Autónoma de Lisboa, 2019. ISSN: 2182-4339 [Disponível em: www.estudoprevio.net]. DOI: https://doi.org/10.26619/2182-4339/16EV

Artigo recebido a 20 de novembro de 2018 e aceite para publicação a 12 de dezembro de 2019. Creative Commons, licença CC BY-4.0: https://creativecommons.org/licenses/by/4.0/

\section{Sobre as maquetas}

É difícil escrever sobre maquetas. Abrem caminhos para a obra que está por vir. As obras estão lá, construídas, em confronto com o mundo e com o tempo. As obras são artefactos destinados à vida e por esta completados. A densidade da construção física não está - não pode estar - nas maquetas. Aí encontramos uma outra forma de conhecer o mundo, pouco importa se construído. Os desenhos de arquitetura e as maquetas estão a tatear o território, estão a ensaiar as proporções, falam-nos eventualmente de uma árvore, estão a partir do princípio que a arquitetura pode monopolizar todos os imprevistos, estão a formalizar o desejo do arquiteto. Talvez por isso constituam um mundo por si só que muitas vezes prescinde da obra construída. $\mathrm{O}$ desenho e as maquetas são a mais otimista das ferramentas.

Palavras-Chave: Arquitetura, ensino, ensaio visual, maquetas 


\section{estudoprévio}

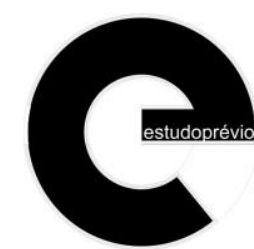

PT | P04 | EP16| w2019
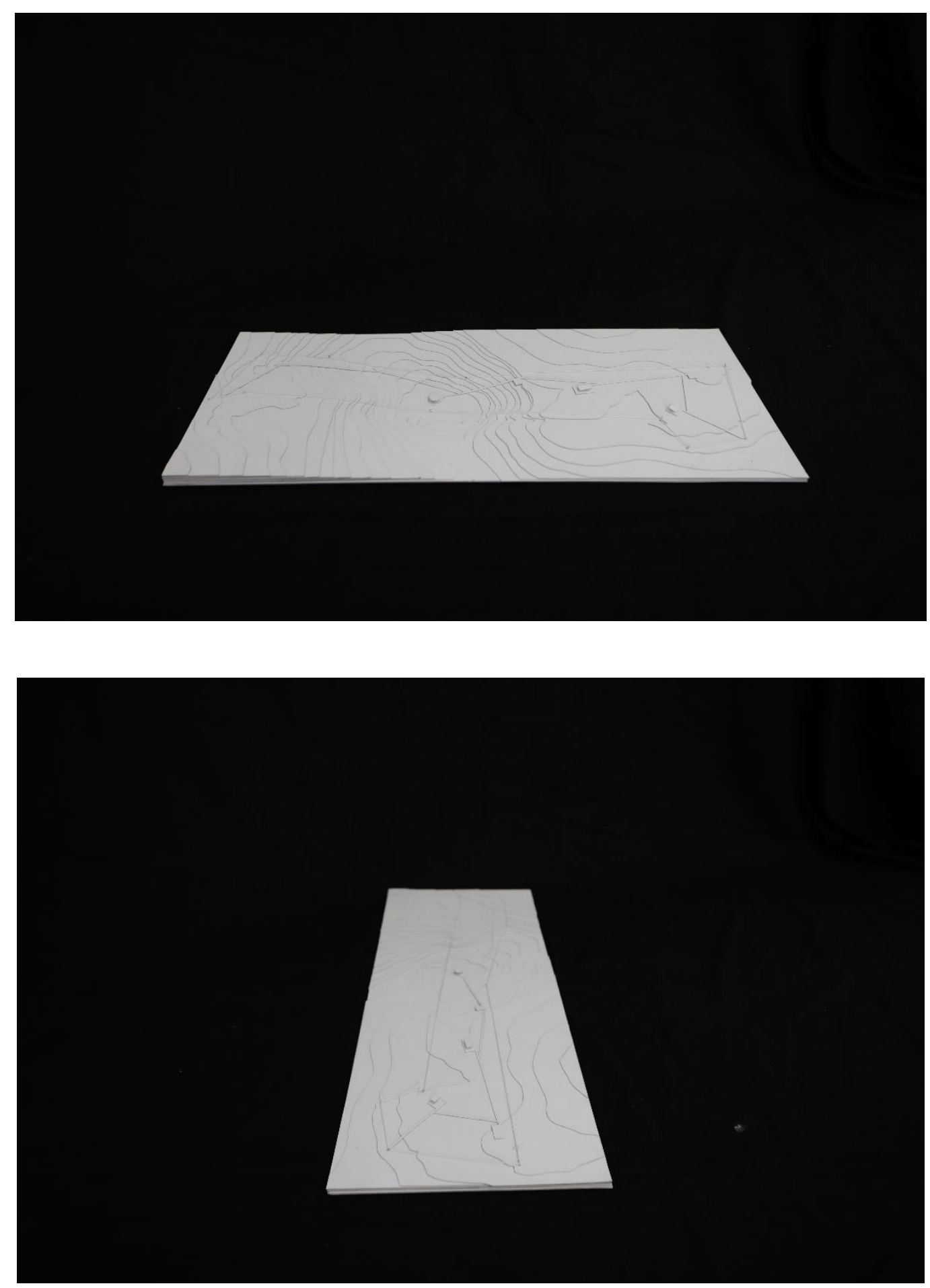


\section{estudoprévio}

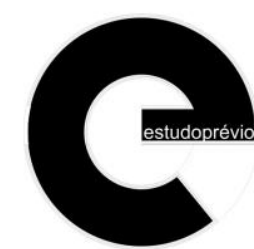

PT | P04 | EP16| w2019
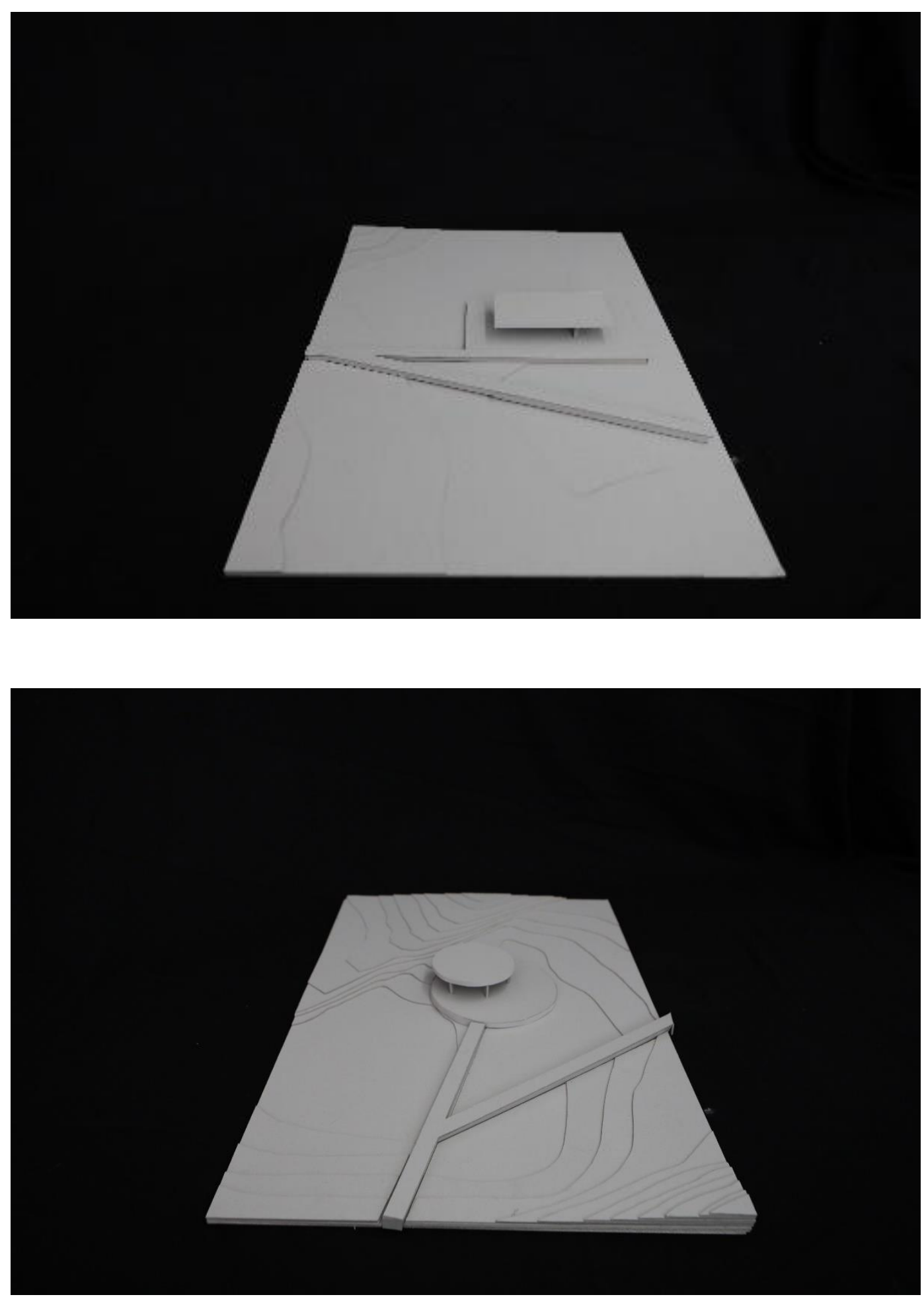


\section{estudoprévio}

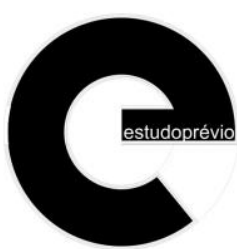

PT | P04 | EP16| w2019
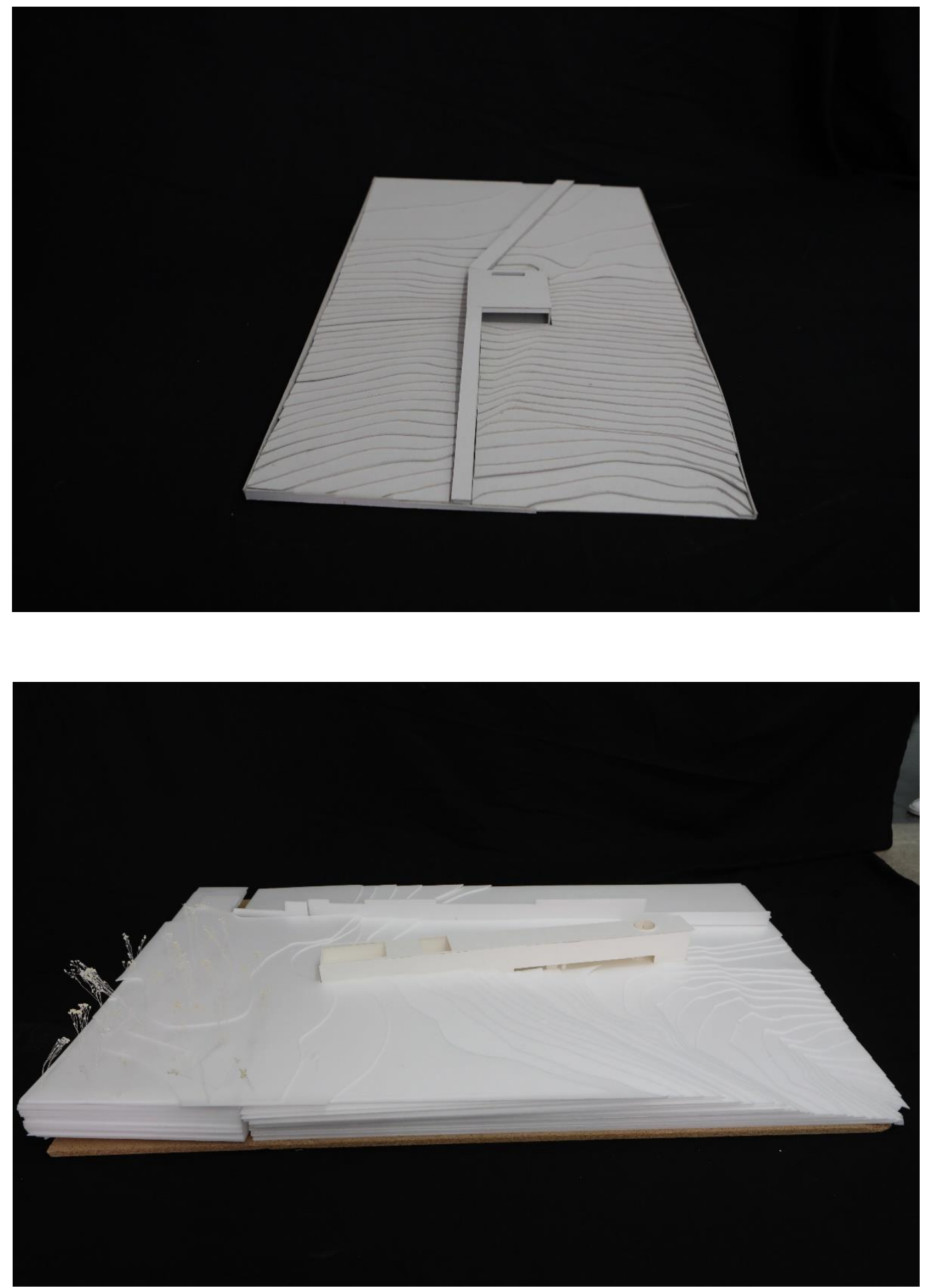


\section{estudoprévio}

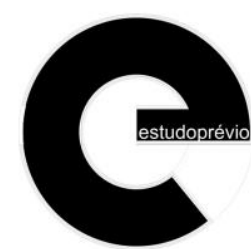

PT | P04 | EP16| w2019
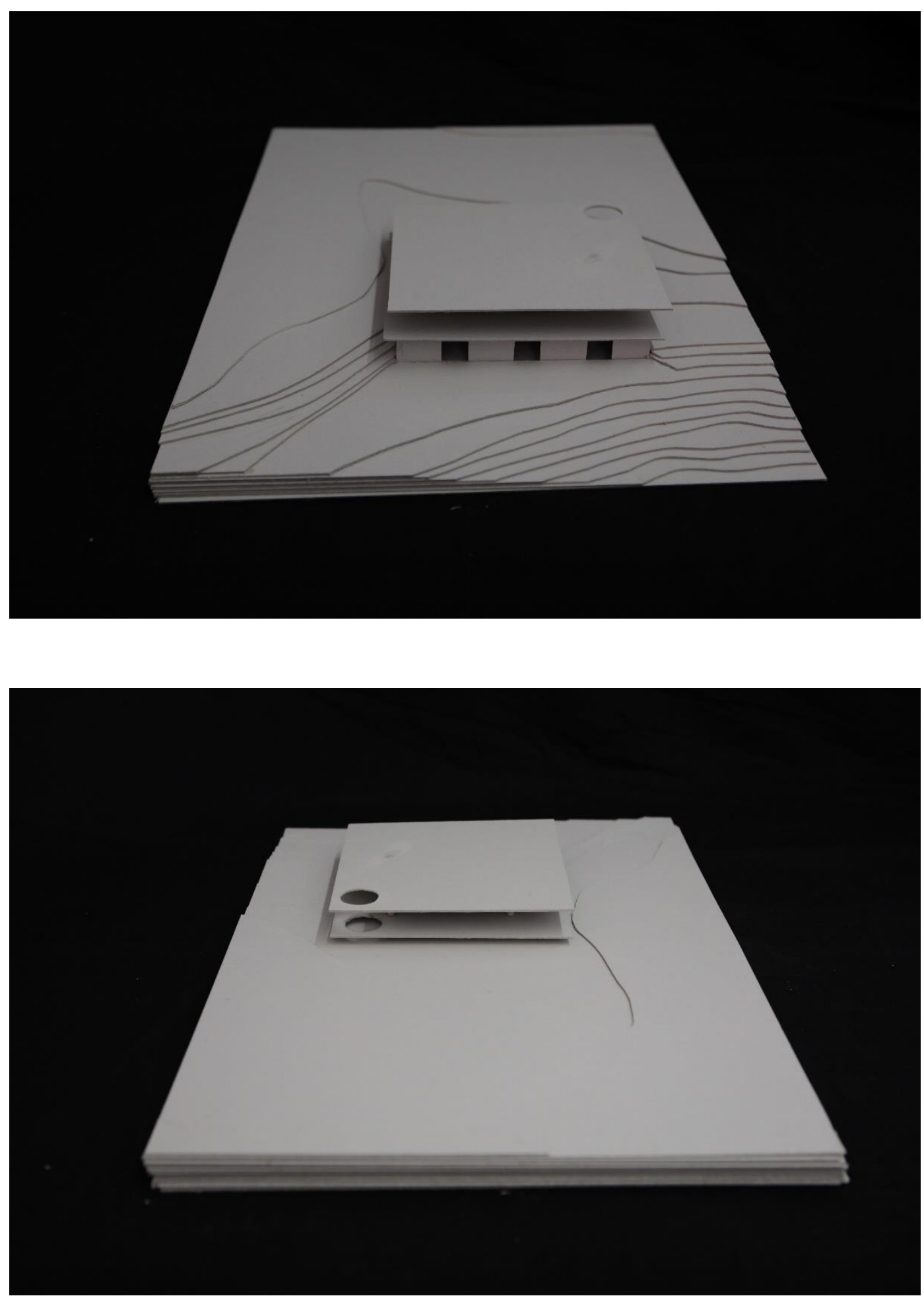


\section{estudoprévio}

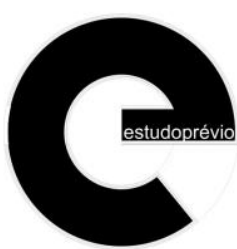

PT | P04 | EP16| w2019
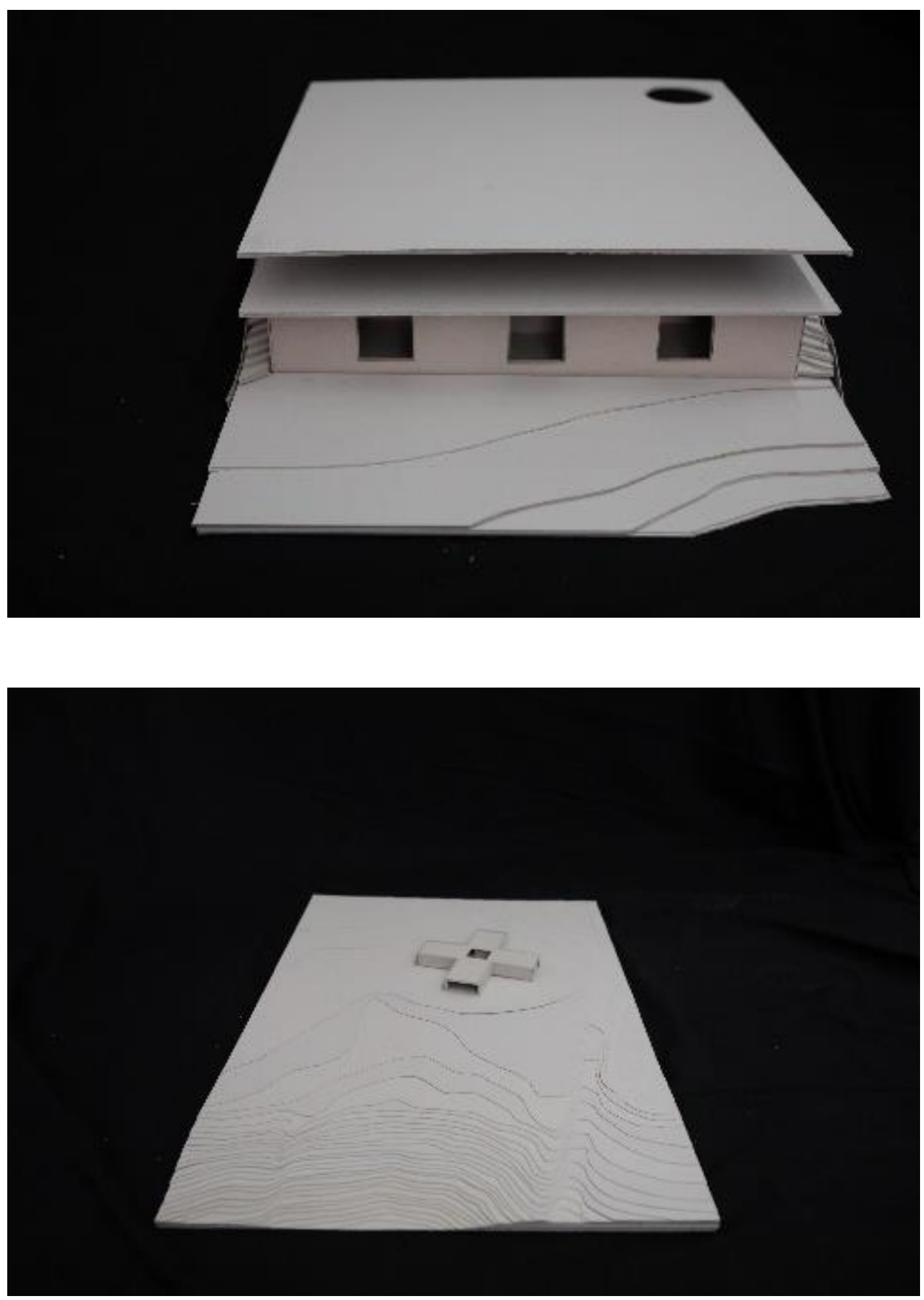


\section{estudoprévio}

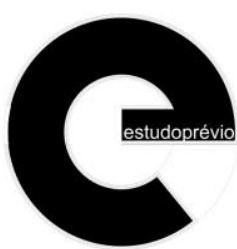

PT | P04 | EP16| w2019
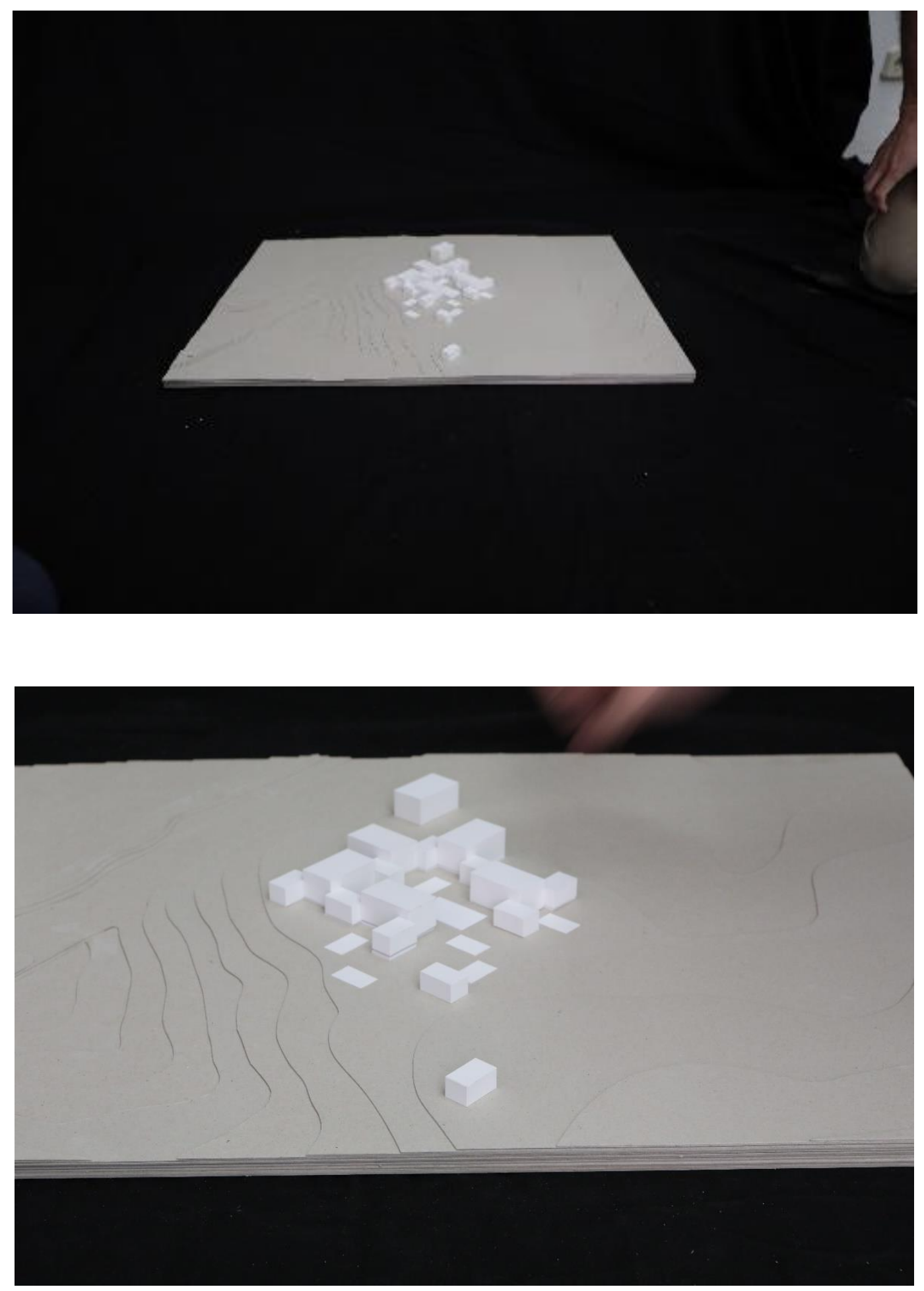


\section{estudoprévio}

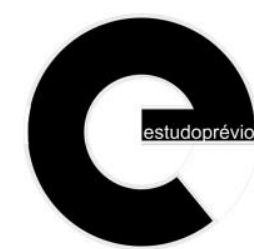

PT | P04 | EP16| w2019
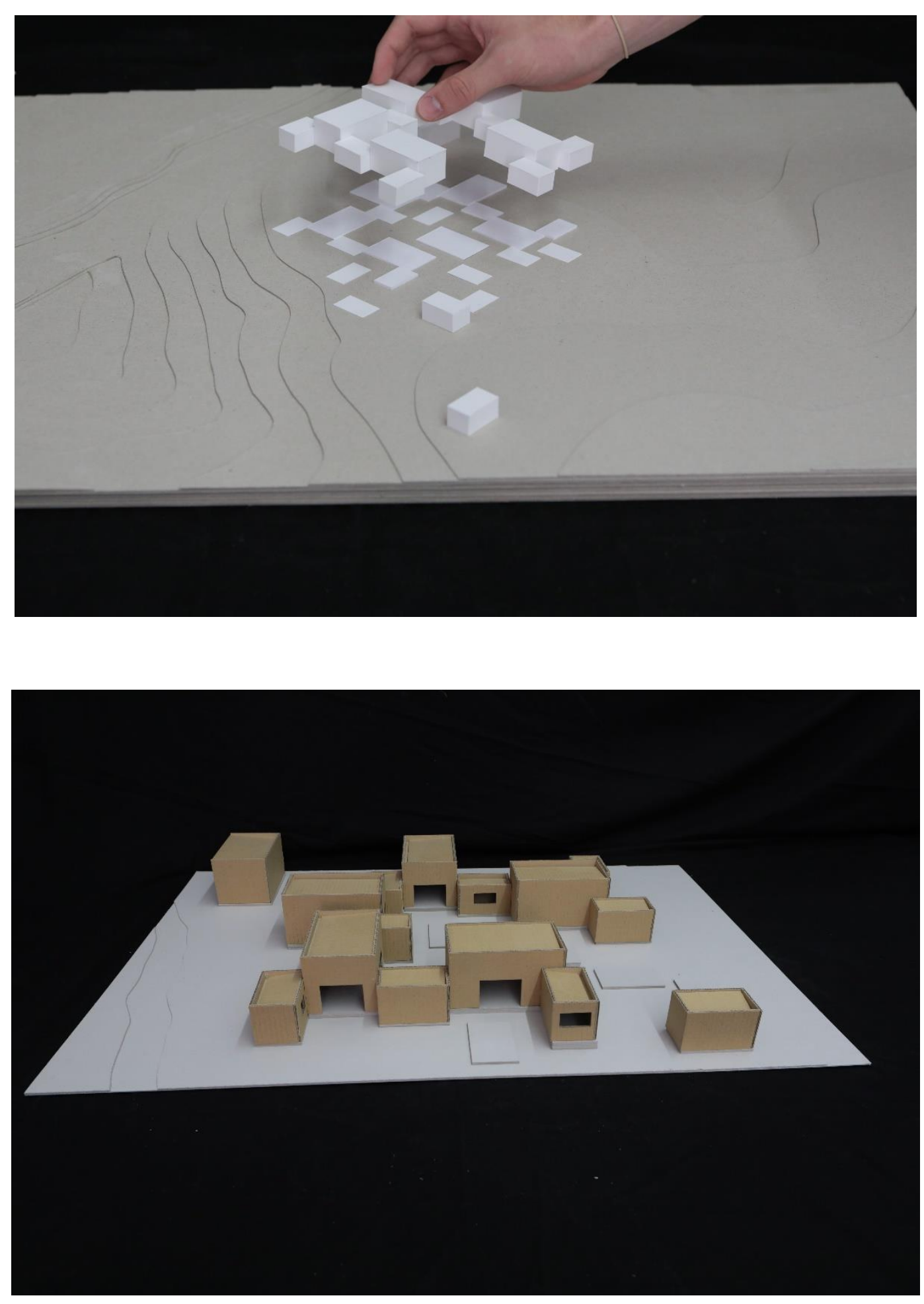


\section{estudoprévio}

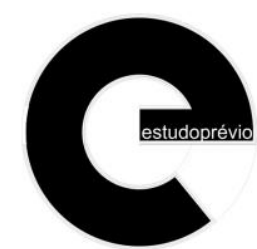

PT | P04 | EP16| w2019
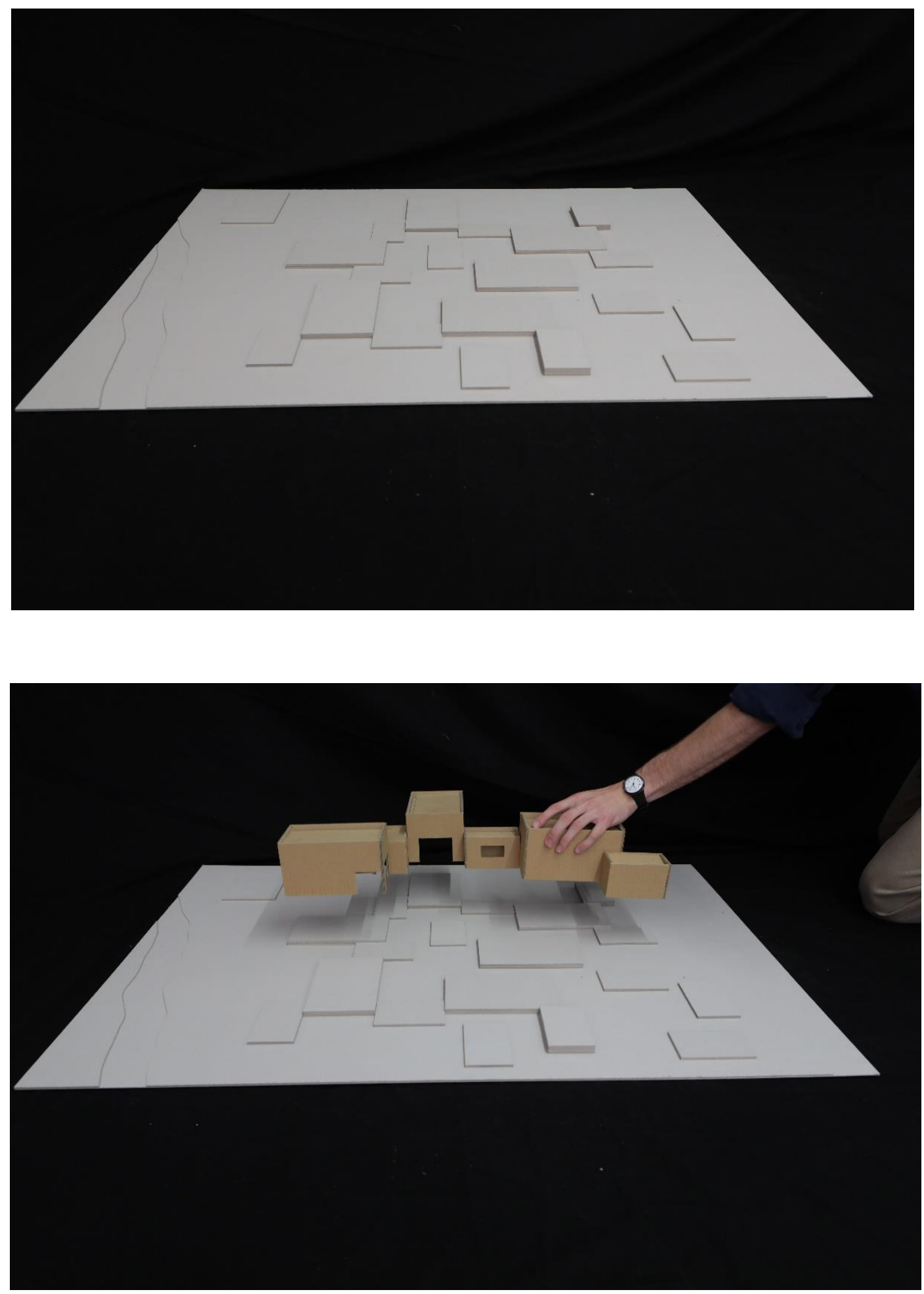


\section{estudoprévio}

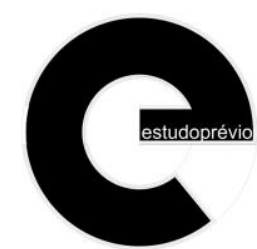

PT | P04 | EP16| w2019
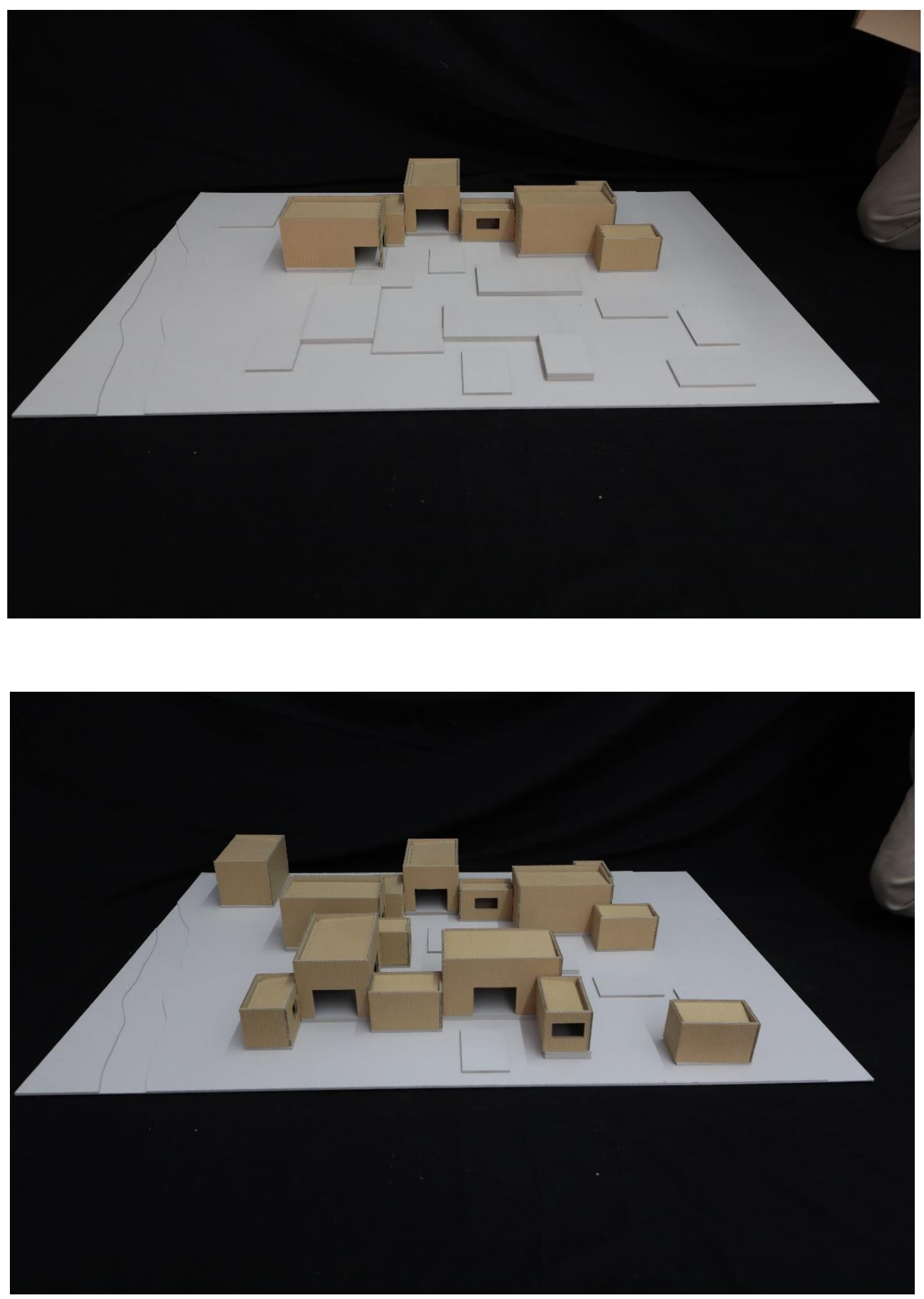


\section{estudoprévio}

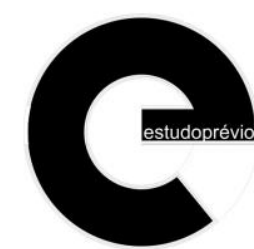

PT | P04 | EP16| w2019
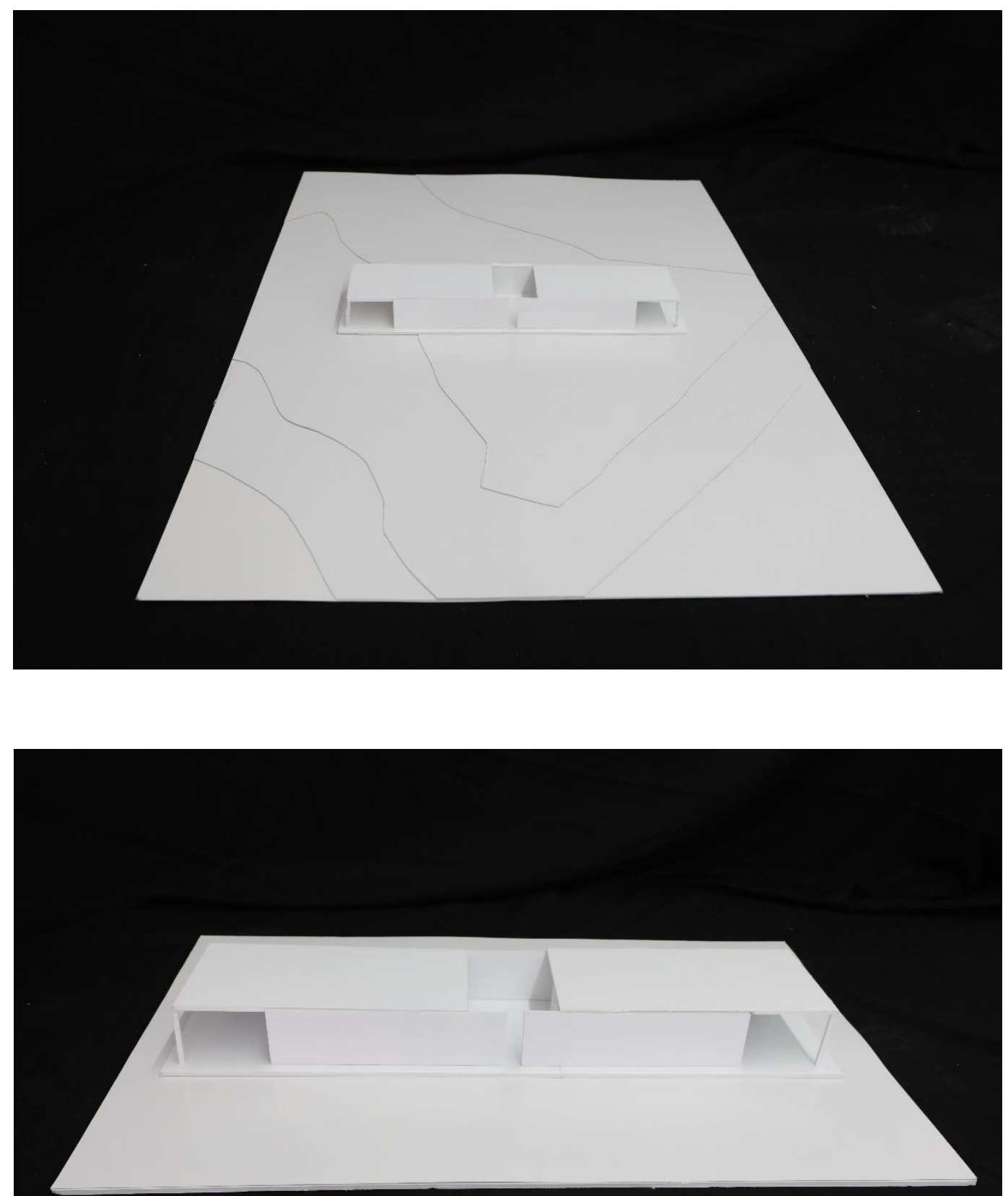


\section{estudoprévio}

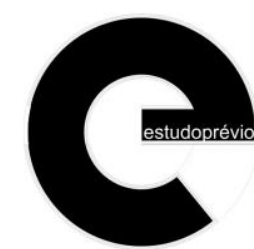

PT | P04 | EP16| w2019
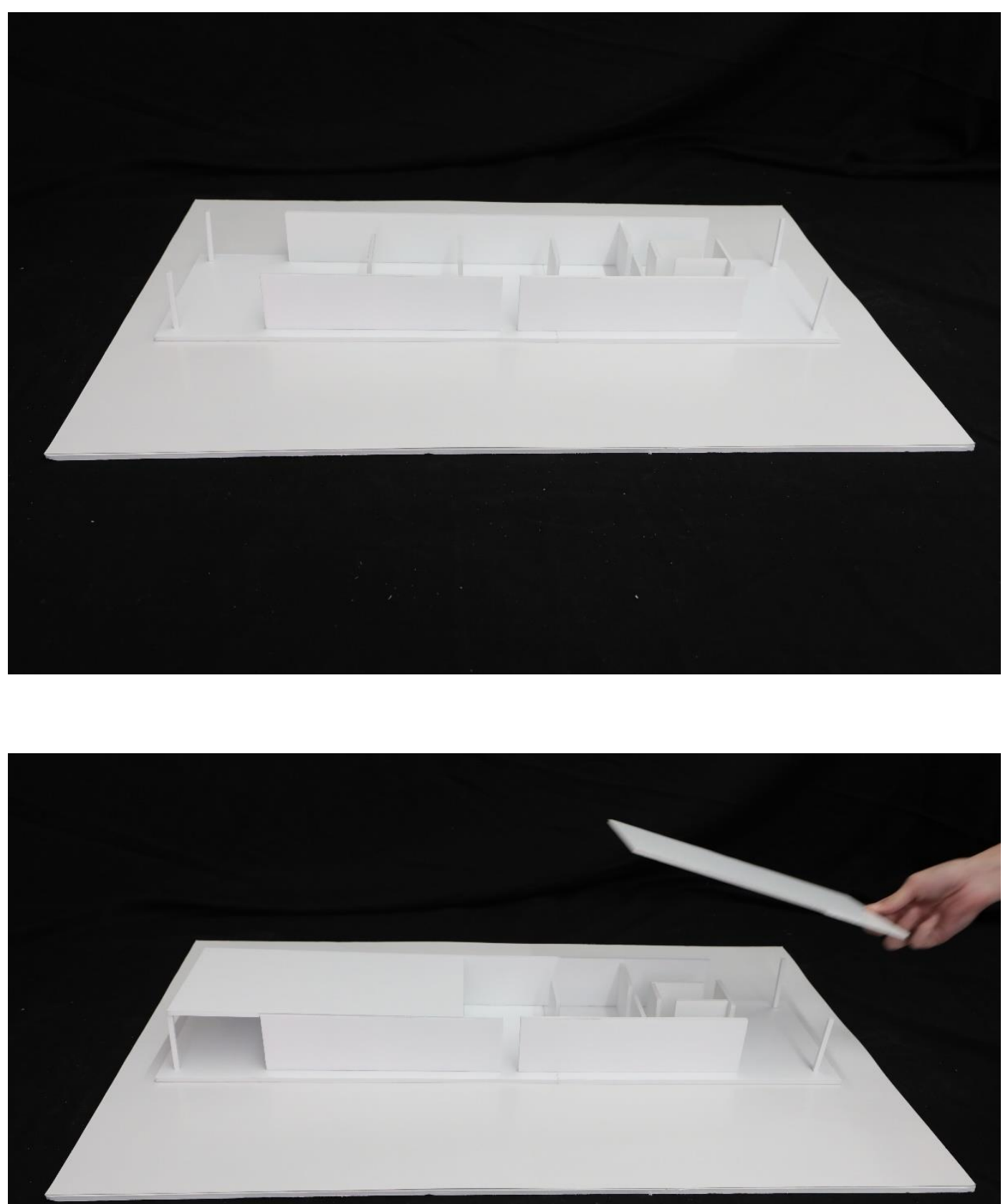


\section{estudoprévio}

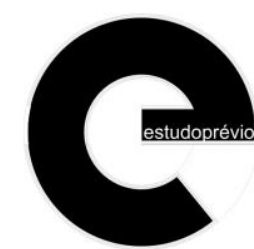

PT | P04 | EP16| w2019
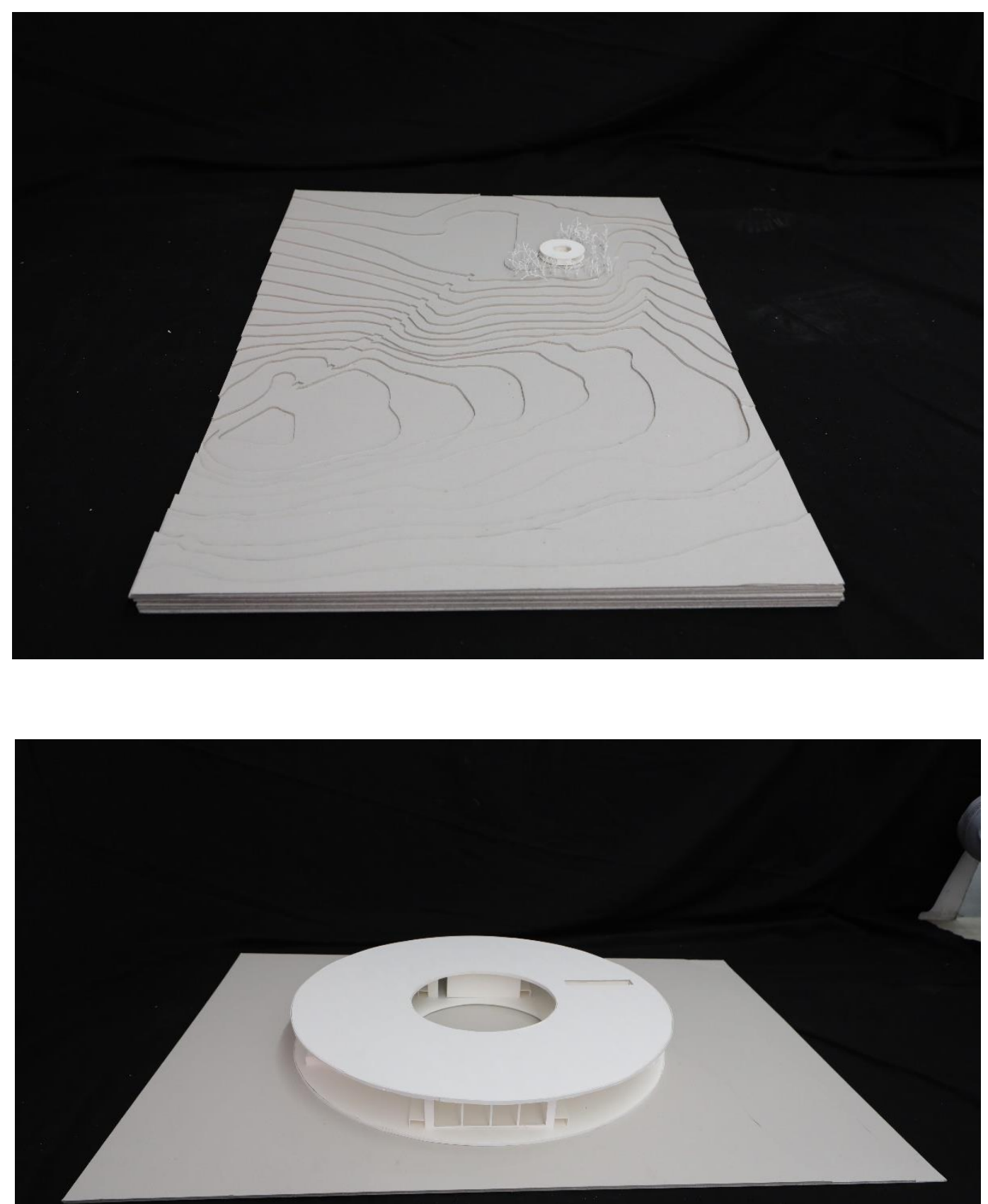


\section{estudoprévio}

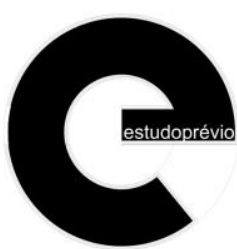

PT | P04 | EP16| w2019
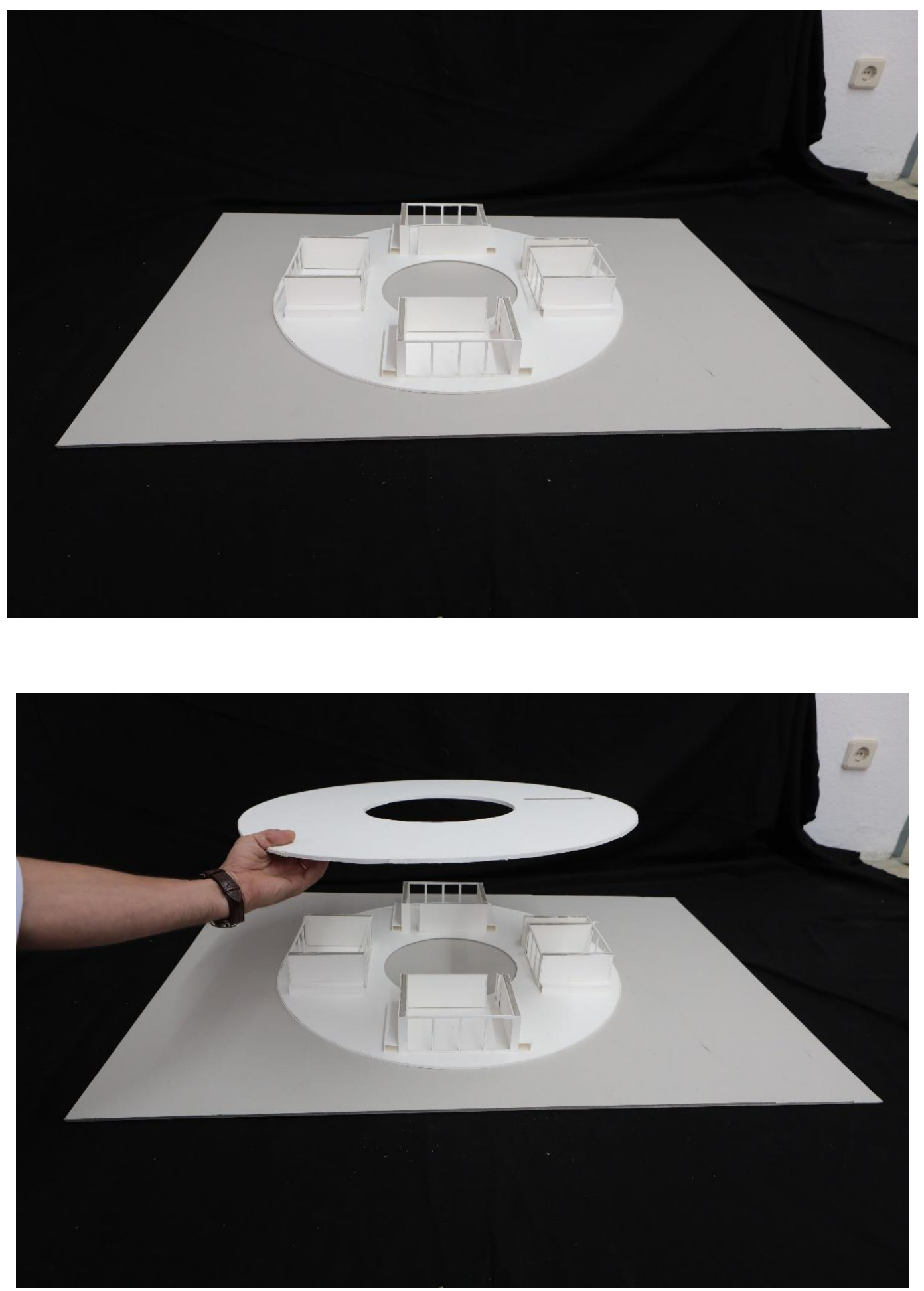


\section{estudoprévio}

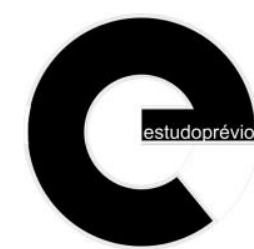

PT | P04 | EP16| w2019
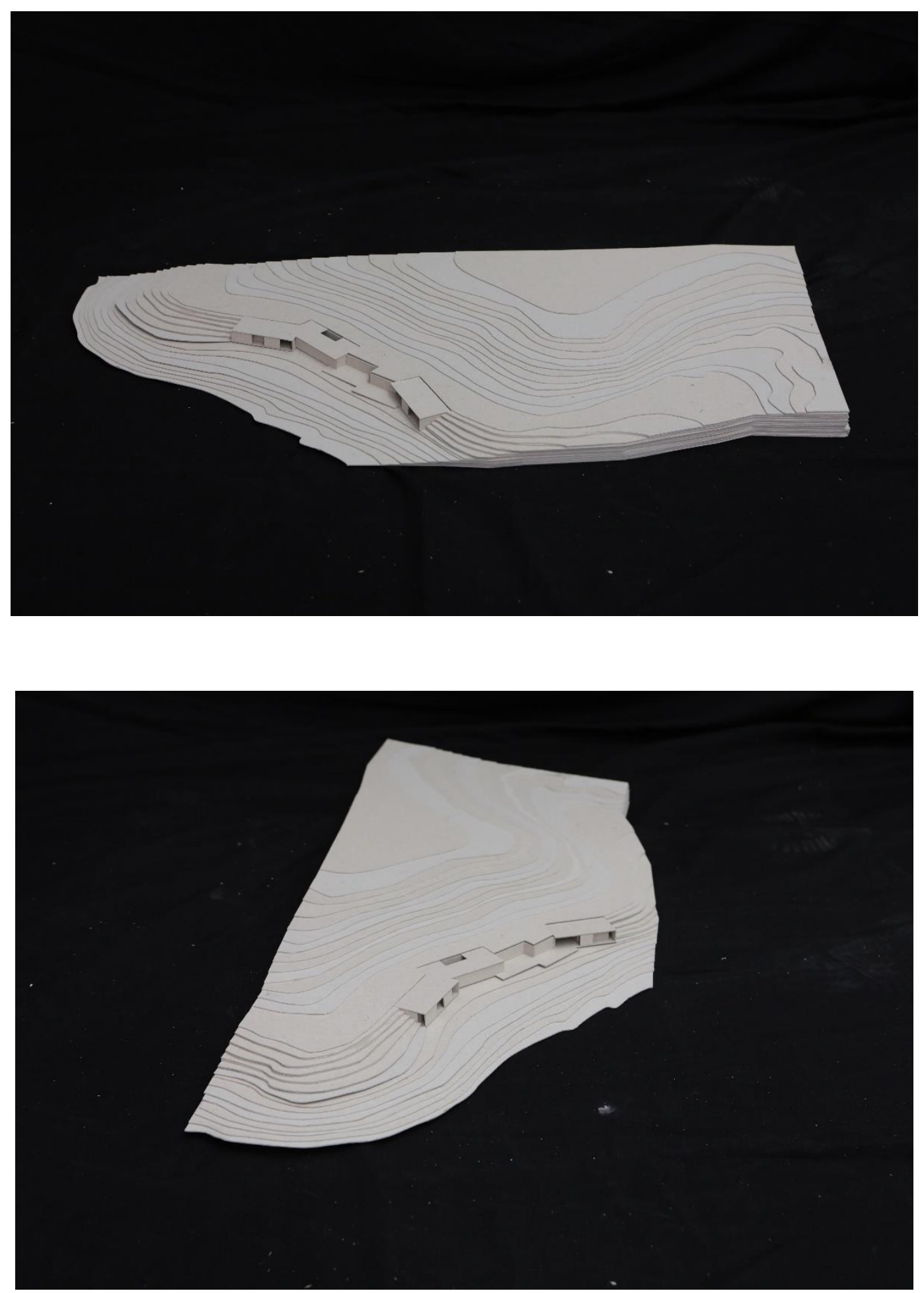


\section{estudoprévio}

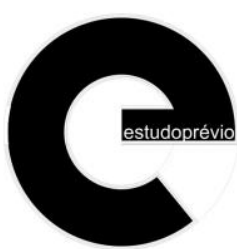

PT | P04 | EP16| w2019
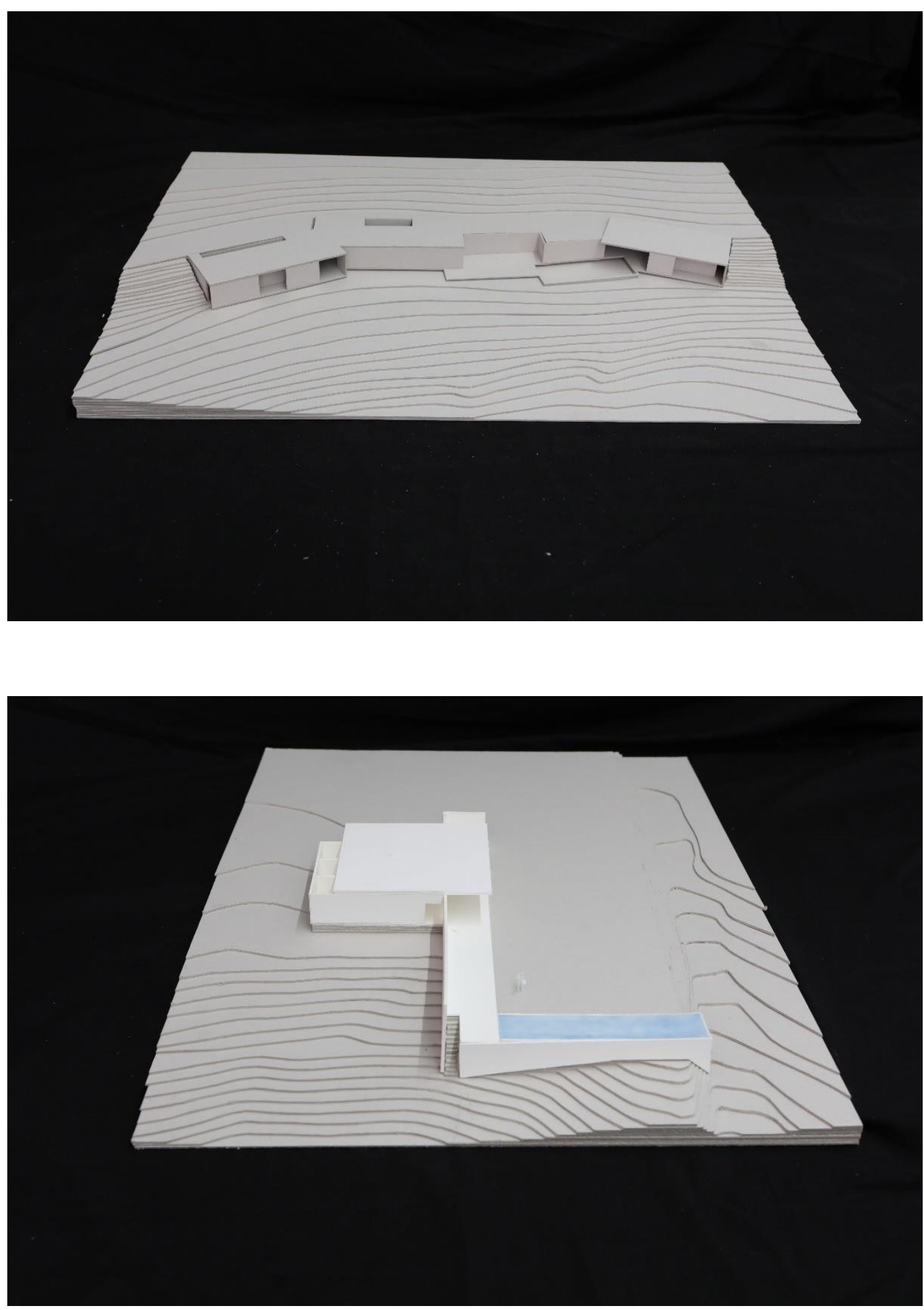


\section{estudoprévio}

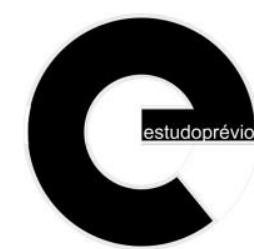

PT | P04 | EP16| w2019
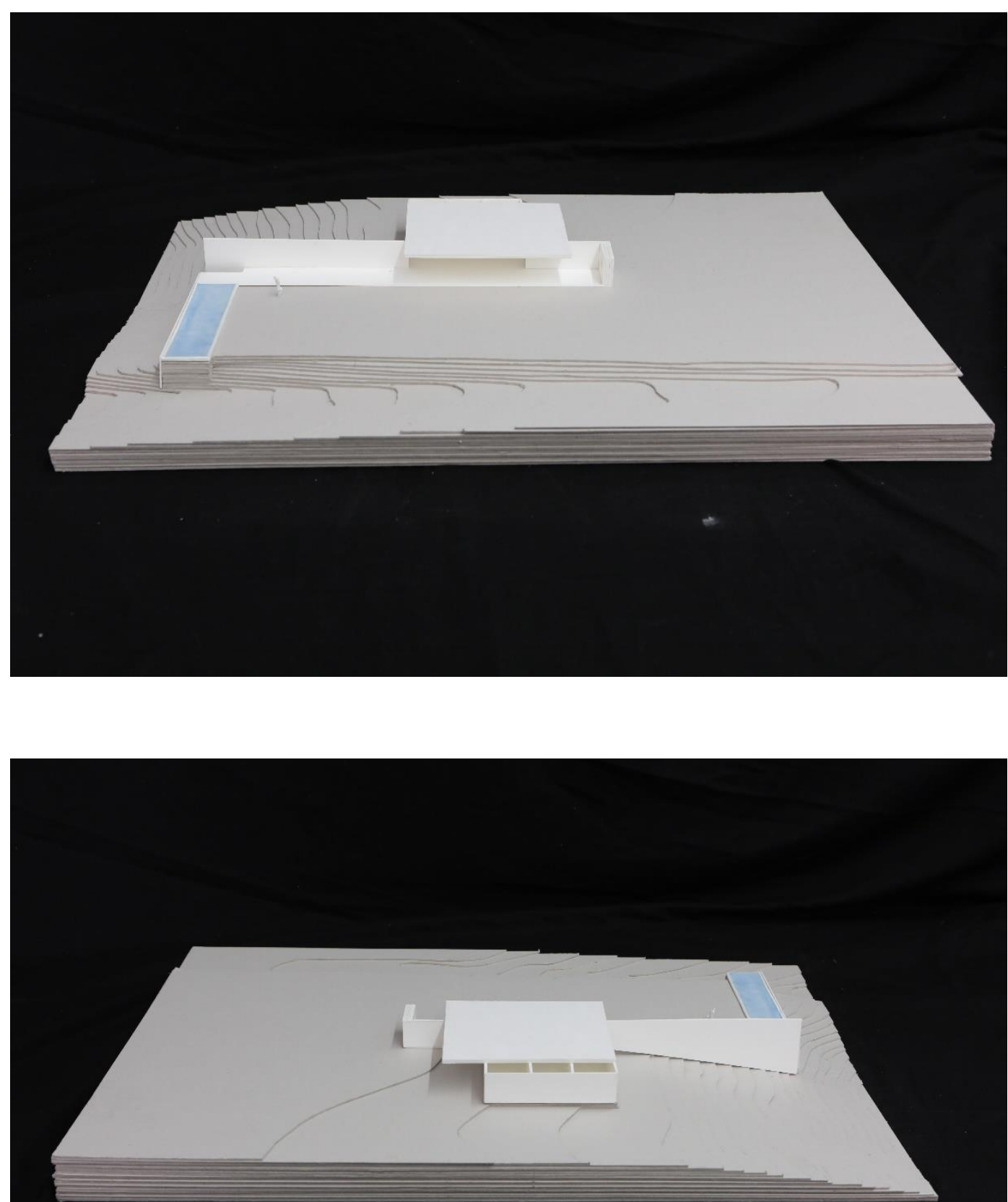


\section{estudoprévio}

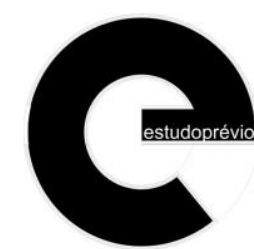

PT | P04 | EP16| w2019
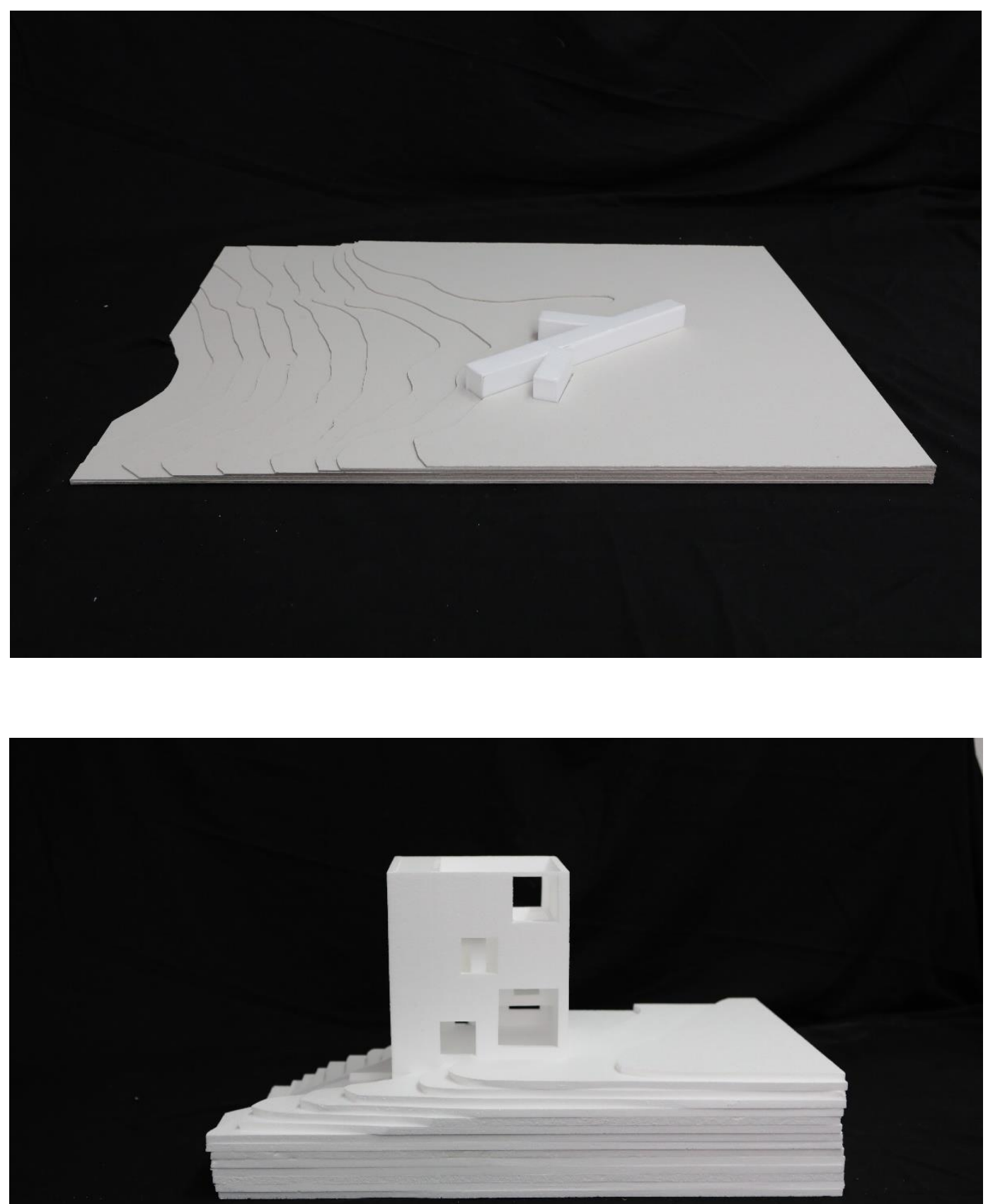


\section{estudoprévio}

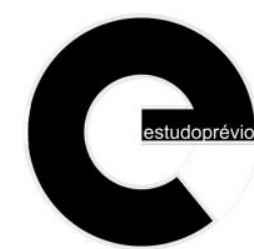

PT | P04 | EP16| w2019
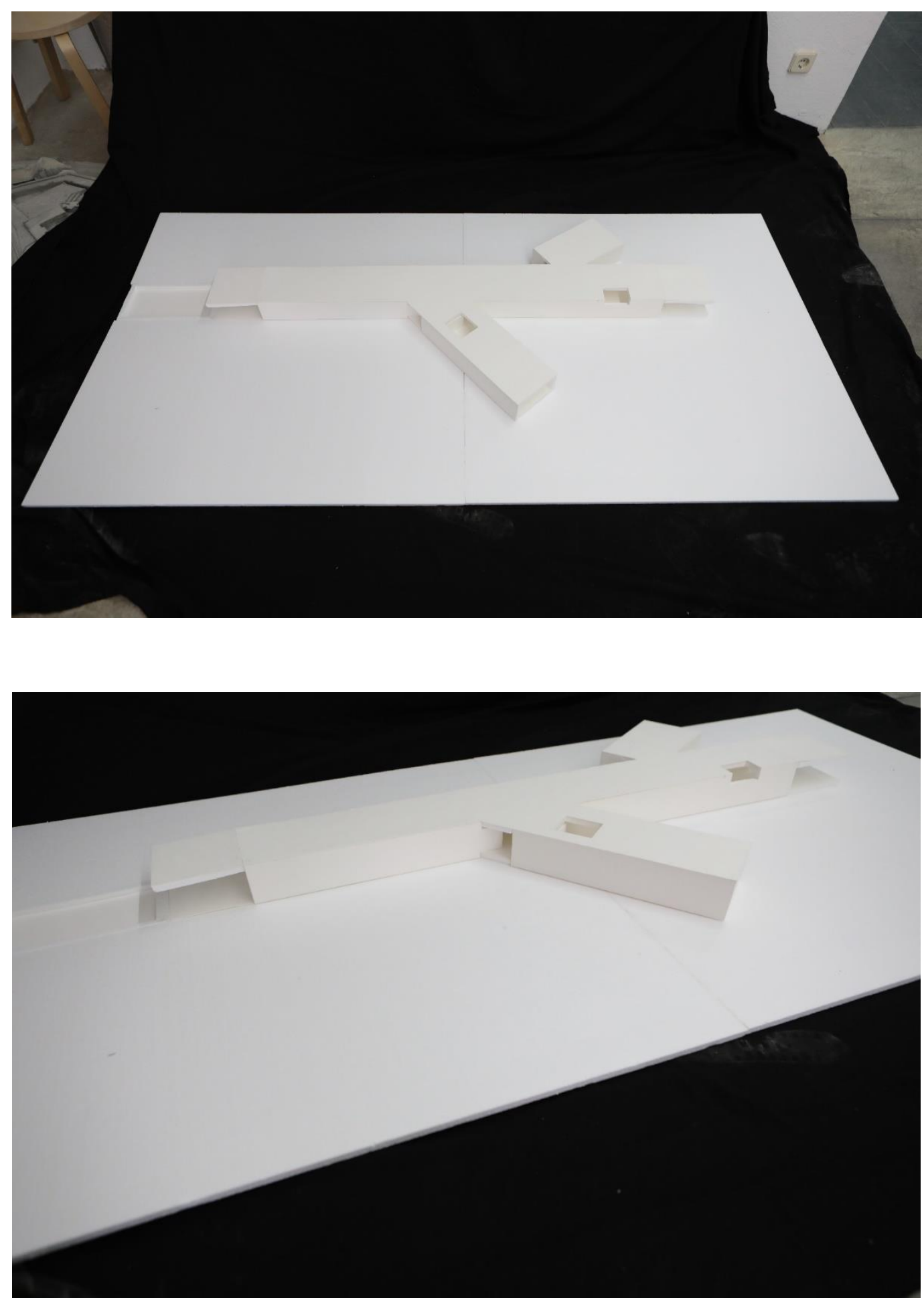


\section{estudoprévio}

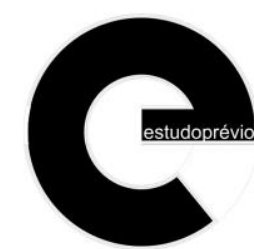

PT | P04 | EP16| w2019
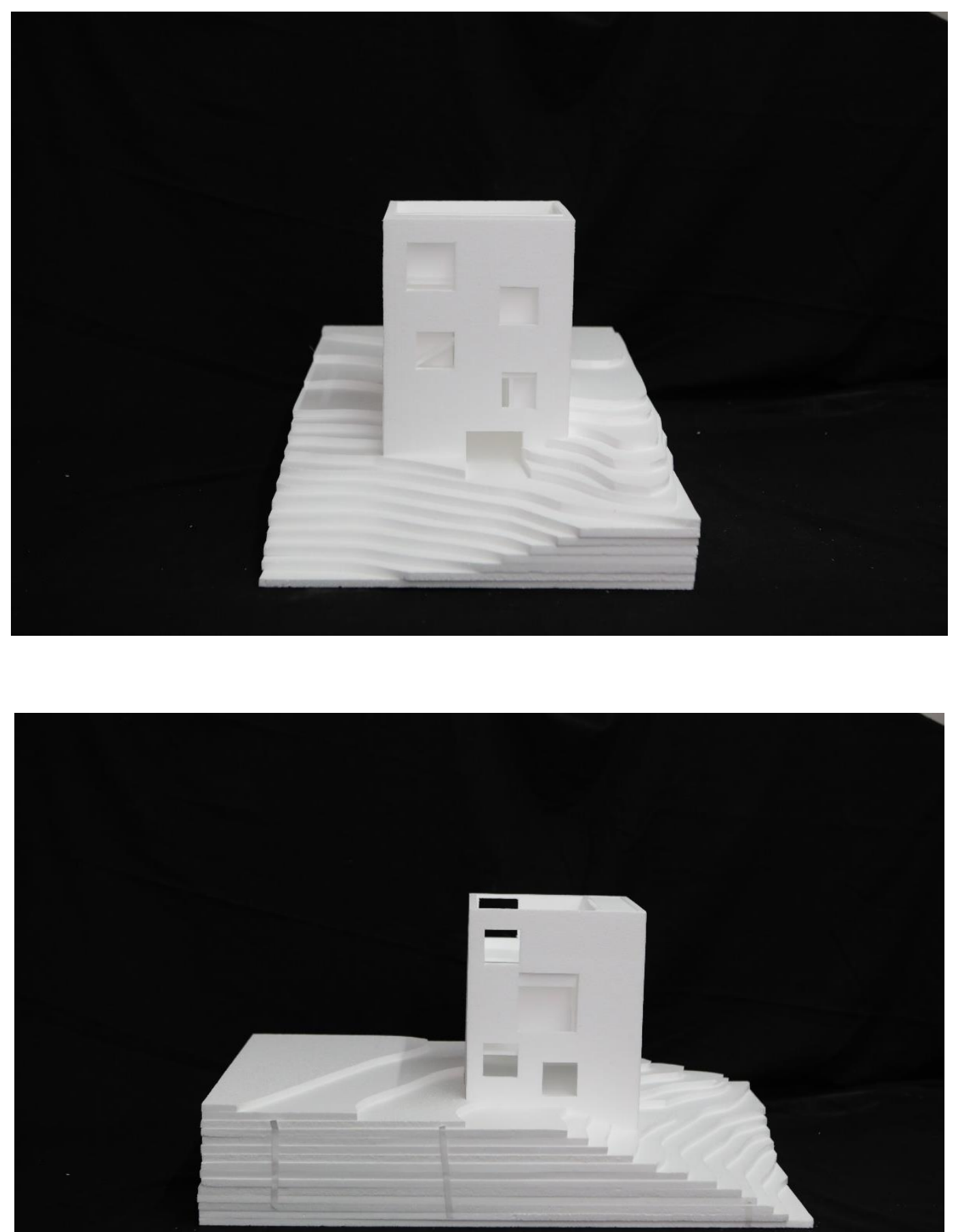


\section{estudoprévio}

Estudos de Arquitectura, Cidade e Território da Universidade Autónoma de Lisboa

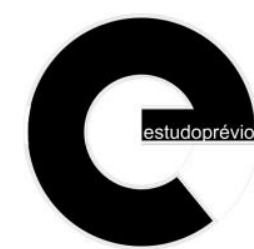

PT | P04 | EP16| w2019

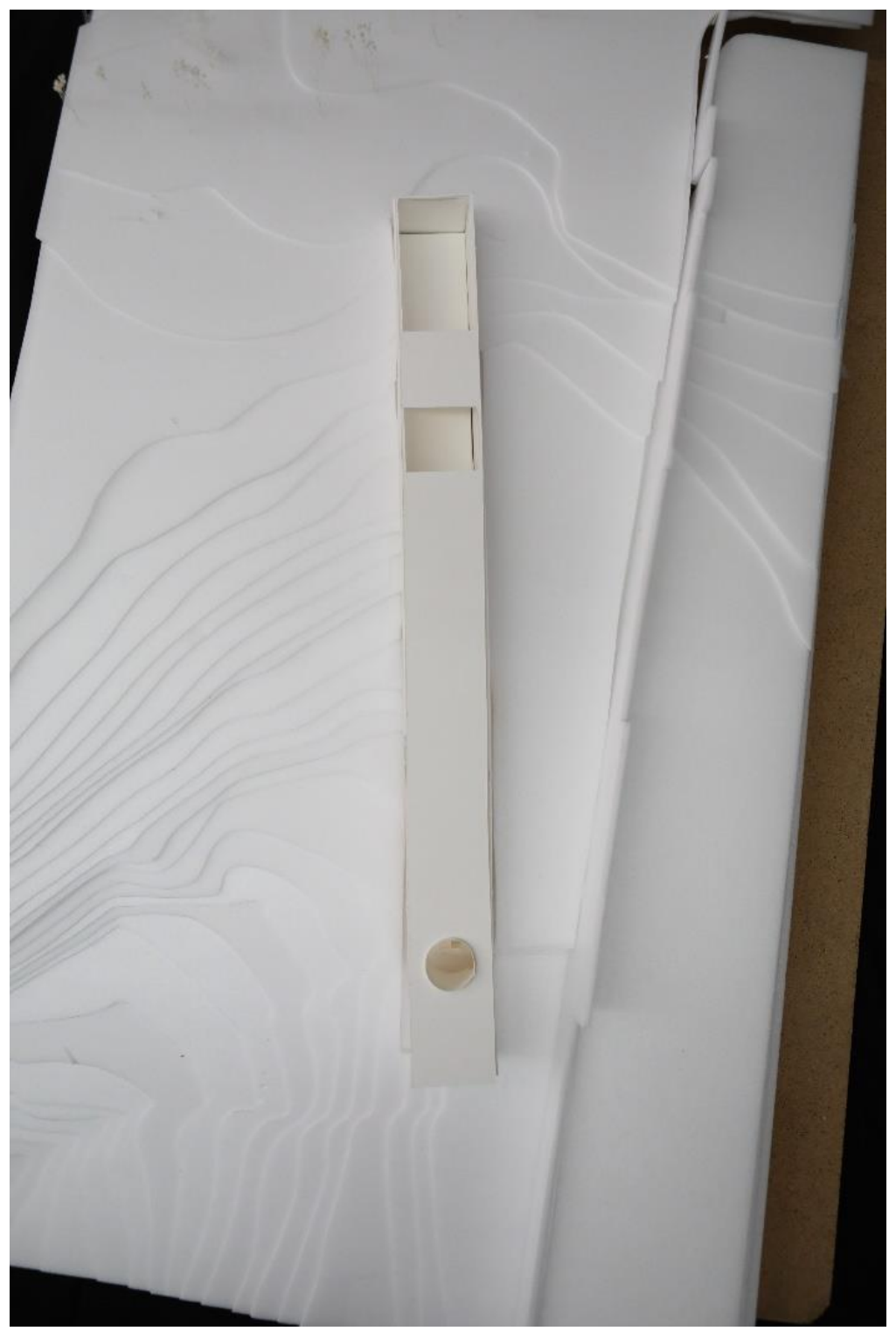

Créditos: Disciplina de Projeto VI 2018/2019. Docentes: Ricardo Carvalho e José Adrião. Alunos: Eliandro Gourgel, Filipa Cunha, Giovanna Rigolin, Henrique Henriques, Matteo Ravano, Odete Silva, Paula Zinn, Rodrigo Marin. Fotografias: Nuno Almendra + estudoprevio

\section{Biografia:}

Ricardo Carvalho é arquiteto e professor universitário. Foi o fundador do Atelier Ricardo Carvalho Arquitectos \& Associados, baseado em Lisboa. Entre as suas obras ocntruídas destacam-se a MUDE (2009-2016) e o Edifício Ribeira 11, ambos em Lisboa. É doutorado em Arquitetua pelo Instituto Superior Técnico e Professor do Departamento de Arquitetura da 


\section{estudoprévio}

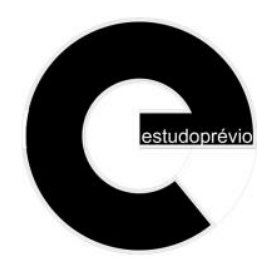

PT | P04 | EP16| w2019

Universidade Autónoma de Lisboa. Foi professor convidado na UNAV de Pamplona, Espanha, na Universidade de Carlton, Canadá e na IUAV Veneza, Itália. Em 2016 publicou o livro "A Cidade Social". Vive e trabalha em Lisboa. 